\title{
Determination of Polycyclic Aromatic Hydrocarbons in kerosene and bio-kerosene soot
}

\author{
Auréa Andrade-Eiroa*, Valérie Leroy, Philippe Dagaut, Yuri Bedjanian \\ CNRS, Institut de Combustion, Aérothermique, Réactivité et Environnement (ICARE), 1C, Avenue de la recherche scientifique - 45071 Orléans Cedex 2, France
}

\section{A R T I C L E I N F O}

\section{Article history:}

Received 16 November 2009

Received in revised form 5 January 2010

Accepted 5 January 2010

Available online 8 February 2010

\section{Keywords:}

Polycyclic Aromatic Hydrocarbons (PAHs)

Kerosene soot

Ultrasonication

Solid Phase Extraction (SPE)

Reverse Phase Liquid Chromatography

(RPLC)

\begin{abstract}
A B S T R A C T
Here we report a new, efficient and reliable analytical methodology for sensitive and selective quantification of Polycyclic Aromatic Hydrocarbons (PAHs) in soot samples. The methodology developed is based on ultrasonic extraction of the soot-bound PAHs into small volumes of acetonitrile, purification of the extracts through $\mathrm{C}_{18}$ Solid Phase Extraction (SPE) cartridges and analysis by Reverse Phase Liquid Chromatography (RPLC) with UV and fluorimetric detection.

For the first time, we report the convenience of adapting the SPE procedure to the nature of the soot samples. As a matter of fact, extracts containing high percentage of unpolar material are recommended to be cleaned with acetone, whereas extracts poor in unpolar compounds can be efficiently cleaned with methanol.

The method was satisfactorily applied to kerosene and bio-kerosene soot from atmospheric open diffusion flames (pool fires) and premixed flames achieving Quantification and Detection limits in the range $\mathrm{ng} \mathrm{mg^{-1 }}$ soot and recoveries about $90 \%$ for most of the PAHs studied.
\end{abstract}

(C) 2010 Elsevier Ltd. All rights reserved.

\section{Introduction}

Although the mechanism of soot formation and growth is not completely understood (Frenklach, 2002), Polycyclic Aromatic Hydrocarbons (PAHs) are supposed to be the key gaseous precursors of soot particles (Haynes and Wagner, 1981) and to be partly entrapped within the soot matrix, included in small pores or strongly sorbed to flat surfaces (Gustafsson and Gschwend, 1997). Currently worldwide soot production is enormous (approximately $150 \mathrm{Tg}_{\text {year }}^{-1}$ ) (IPCC, 2001), both of them, soot and PAHs are important environmental issues. Moreover, accurate quantification of PAHs in soot would be useful for elucidation of soot formation in the combustion field. Thus, it is extremely important to develop an efficient analytical methodology for accurate quantification of PAHs in soot samples. This methodology should include a proper extraction methodology, clean-up of the extracts and accurate detection (if necessary) and sensitive quantification of the target analytes.

Regarding the extraction procedure, ultrasonic extraction by using a horn-type device equipped with titanium tip was selected because it is recommended by the US Environmental Protection Agency for solid samples (Method 3550A, US-EPA). Although the extraction of strongly bound soot-associated PAHs is a difficult

\footnotetext{
* Corresponding author. Tel.: +33 30238255462.

E-mail addresses: eiroa_2000@yahoo.es, andrade@cnrs-orleans.fr (A. AndradeEiroa).
}

task, the effectiveness of ultrasonication has been demonstrated by a number of authors (Hechler et al., 1995; Christensen et al., 2005). Furthermore, PAHs seem to resist ultrasonic probe energy, which is not the case for other unwanted organic compounds adsorbed on soot surface.

HPLC with UV or fluorimetric detection was chosen due to its high sensitivity. However and unlike GC/MS, HPLC methodology in combination with fluorimetric detection of PAHs requires extracts to be purified prior analysis. In fact, the fluorescence signals of PAHs can be efficiently quenched by other co-eluting organic compounds present in environmental matrixes, including alkylPAHs, aliphatic compounds, and a number of polar compounds (Lamprecht and Huber, 1992; Christensen et al., 2005; Albinet et al., 2006) extracted along with PAHs from soot and consequently, samples should be purified before HPLC analysis as we will demonstrate in this paper.

In recent studies, Solid Phase Extraction (SPE) columns have been demonstrated to be more efficient than other purification techniques for removing matrix effect in environmental samples (Fladung, 1995; Jonker and Koelmans, 2002; Christensen, 2003; Christensen et al., 2005). Regarding this step, we introduce the idea of adapting the SPE clean-up procedure to the nature of soot for improving the efficiency of purification.

This work was conducted primarily because there are a limited number of published analytical methods for quantifying PAHs at the sub microgram range expected in kerosene and bio-kerosene soot samples. Bio-fuels are extremely important nowadays since 
they are expected to reduce the emission of highly carcinogenic pollutants such as PAHs.

\section{Experimental}

\subsection{Chemicals and solutions}

A mixture of 17 PAHs (2000 $\mu \mathrm{g} \mathrm{mL}^{-1}$ each component in methylene chloride: benzene (1:1)) from Sigma-Aldrich was used for preparation of standards by dilution. Components in the mixture were: acenapthene (Ace), acenaphthylene (Acy), anthracene (Ant), benzo[a]anthracene (BaA), benzo[b]fluoranthene (BbF), benzo[k]fluoranthene $(\mathrm{BkF})$, benzo[g,h,i]peyrlene (BghiP), benzo[a]pyrene (BaP), chrysene (Chry), dibenzo[a,h]anthracene (DBa$\mathrm{hA}$ ), fluoranthene (Flu), fluorene (Fl), indeno[1,2,3-cd]pyrene (IdP), 2-methylnaphthalene (2MNaph), naphthalene (Naph), phenanthrene (Phe) and pyrene (Pyr). Coronene (Cor) and anthanthrene (Antha) were supplied by Sigma-Aldrich.

Hexane for residue analysis (Fluka, Riedel-de Haën) and methanol (R.P. Normapur AR for analysis from Prolabo) were used. Water, 2-propanol and acetonitrile of HPLC grade were obtained from Sigma Aldrich. Kerosene used for soot generation was a commercial Jet-A1. A mixture of Jet-A1 and rapeseed oil methyl ester (RME, consists of a complex mixture of $C_{14}-C_{22}$ methyl esters with highly saturated carbon chains) (80/20) was used as bio-kerosene (Dagaut and Gail, 2007).

\subsection{Preparation of soot samples}

Soot samples were collected in open diffusion (pool fires) and premixed flames of kerosene and bio-kerosene fuels.

\subsubsection{Soot sampling in open diffusion flame}

The pool fire experimental setup consisted of a stainless steel conical container $\left(14 \mathrm{~cm}\right.$ in diameter, $\left.82^{\circ}\right)$ where $25 \mathrm{~mL}$ of fuel (kerosene or bio-kerosene) were burned under ambient conditions producing open diffusion flames. The soot samples were collected on a stainless steel grid ( $0.5 \mathrm{~mm}$ diameter holes, $16 \mathrm{~cm}$ diameter) placed inside an aspiration hood, $50 \mathrm{~cm}$ above the liquid. Two types of soot were collected: the first one belonged to complete combustion procedures (sampling time being near $7 \mathrm{~min}$ ), and the second one belonged to the first stage of the combustion process (incomplete combustion) with sampling time of $3.5 \mathrm{~min}$. Collected soot was weighed, placed in borosilicate glass test tubes containing $4 \mathrm{~mL}$ of acetonitrile and stored at $4{ }^{\circ} \mathrm{C}$ until analysis.

\subsubsection{Soot sampling in a premixed flame}

A flat-flame burner used for generating soot (Lelièvre et al., 2004) allowed the preparation of soot samples from premixed flames of liquid fuels in a reproducible way and under well controlled combustion conditions. The liquid fuel pumped with a Gilson pump was first atomized by forcing it through a small orifice by a high pressure (a few atm) nitrogen jet and then vaporized in a heated chamber. Then oxygen and nitrogen flows were added to this fuel vapor - nitrogen mixture. The flow rates of nitrogen and oxygen were measured with mass flow controllers. The matrix of the burner was placed into a Pyrex tube to prevent the flame perturbation by external air movements. Soot samples from stabilized premixed flames of kerosene (or bio-kerosene) were collected on the external walls of a Pyrex tube $(0.9 \mathrm{~cm}$ o.d.). This support tube was temperature controlled by circulating of thermostated $\left(45^{\circ} \mathrm{C}\right)$ water inside the tube. This allowed soot collection with a reproducible PAHs content. Another advantage of this configuration is that it avoided water condensation on soot samples.

\subsection{Analysis}

For PAH extraction from soot samples we employed a $750 \mathrm{~W}$, $20 \mathrm{kHz}$ VibraCell 75041 ultrasound pulsed sonicator (Bioblock Scientific) combined with a sonotrode of $3 \mathrm{~mm}$ diameter. We used $0.2 \mu \mathrm{m}$ sealed hydrophobic PTFE membrane filters with PTFE housing from Alltech and Durobax glass syringes of $5 \mathrm{~mL}$ from Poulten \& Graf for filtering soot samples before SPE extraction. Silica, silicaamino, silica-cyano, silica-diol, and silica- $\mathrm{C}_{18}$ bulk from Supelco were housed in clean-up glass columns. A vacuum manifold SPE $12-\mathrm{G}$ from Baker allowed the conditioning of the SPE column and the elution of compounds.

Chromatographic experiments were performed by using a HPLC system from Shimadzu. The instrument consisted of a system controller CBM-20A/20 Alite Prominence, a solvent delivery module LC-20AB Prominence, an autosampler SIL-20A/20AC Prominence, a column oven CTO-20A/20AC Prominence, a UV/Visible photodiode array detector SPD-M20A Prominence and a spectrofluorimetric detector RF-10AxL. A Vydac column $201 \mathrm{TPC}_{18}, 5 \mu \mathrm{m}, 250 \mathrm{~mm}$ length $\times 4.6 \mathrm{~mm}$ ID (Grace Daison Discovery Sciences), was used for the analysis.

Acetonitrile and water were used as mobile phase and the flow rate was set up at $0.5 \mathrm{~mL} \mathrm{~min}{ }^{-1}$. The isocratic gradient was $50 \%$ acetonitrile: water for $30 \mathrm{~min}$, then the linear gradient elution from $50 \%$ acetonitrile at $30 \mathrm{~min}$ to $100 \%$ acetonitrile at $90 \mathrm{~min}$ was applied followed by isocratic elution with $100 \%$ acetonitrile for $5 \mathrm{~min}$ to remove possible impurities adsorbed inside the column. Each run concluded with a conditioning step (50\% water/Acetonitrile) for $7 \mathrm{~min}$. The injection volume was $20 \mu \mathrm{L}$ of SPE extract previously filtered through a $0.2 \mu \mathrm{m}$ sealed hydrophobic PTFE membrane filter with PTFE housing. The column oven temperature was maintained at $30^{\circ} \mathrm{C}$ throughout the analysis. The fluorescence excitation and emission wavelengths were changed during the chromatographic separation in order to obtain better sensitivity. The programmed wavelengths were:

- 220/330 nm until 30 min (naphthalene, 2-methylnaphthalene, acenaphthene and fluorene),

- 251/370 nm until 40 min (phenanthrene and anthracene),

- 236/393 nm until $58 \mathrm{~min}$ (fluoranthene and pyrene), and

- 295/425 nm (benzo[a]anthracene, chrysene, benzo[b]fluoranthene, benzo[k]fluoranthene, benzo[a]pyrene, dibenzo[a,h]anthracene, benzo[g,h,i]perylene, and indeno[1,2,3-cd]pyrene).

\section{Results and discussion}

\subsection{Ultrasonic-assisted extraction}

Currently, there are two basic types of ultrasonic instrumentation available for the analytical chemist: ultrasonic bath and the more powerful probe system (Marín et al., 2001; Nascentes et al., 2001). In the present study, we employed ultrasonic-assisted extraction using high intensity ultrasonic processor combined with sonotrode of $3 \mathrm{~mm}$ diameter to transmit the ultrasound into the liquid. The sample extraction with an ultrasonic processor is significantly faster compared with traditionally used ultrasonic bath due to the higher and focused energy at the probe tip. A few series of experiments were carried out in order to choose appropriate solvent and to optimize the extraction conditions, as described in the following paragraphs.

\subsubsection{Selection of extractant}

The choice of the solvent is an important point in extraction of PAHs from soot since the extraction efficiency depends on the solvent nature. Dichloromethane is the most frequently used 
solvent for PAHs extraction from soot, whereas, other solvents such as hexane, acetone, or toluene have also been used (Jonker and Koelmans, 2002 and references therein).

Comparatives among extractive efficiencies of different solvents reported in the literature are contradictory (Jonker and Koelmans, 2002 and Refs. therein) and do not allowed to draw up definitive conclusions about which it is the best extractant for soot. This can be explained by the fact that optimal extracting solvents are different for different PAHs and for different extraction procedures. Furthermore, the extracting efficiency of a given solvent depends on the soot type and origin.

The extractive efficiencies of PAHs from kerosene soot performed by ultrasound probe and four different solvents (acetonitrile, methanol, dichloromethane, and toluene) were compared (data not shown). The results indicated that the extracting efficiencies of acetonitrile and toluene are somewhat higher than those of methanol and dichloromethane, in particular for heavier PAHs. Acetonitrile was preferred here and used as extraction solvent throughout the present study since it can be directly cleaned-up in the $\mathrm{C}_{18}$ cartridge avoiding change of the solvent.

\subsubsection{Volume of extractant}

The volume of extractant was optimized by evaluation of extraction efficiencies of PAHs from kerosene soot samples (soot mass of a few $\mathrm{mg}$ ) by varying the volume of solvent, i.e. 2, 4, 6 and $10 \mathrm{~mL}$ of acetonitrile (data not shown). No significant difference was observed among extractive efficiencies, although when $2 \mathrm{~mL}$ of extractant is used, the efficiency seems to be very poor, whereas $4 \mathrm{~mL}$ of extractant provided us with recoveries similar to those obtained with $6 \mathrm{~mL}$, and higher than those extracted with $10 \mathrm{~mL}$ of solvant (data not shown).

The same conclusion was drawn up by a number of authors (Pereira et al., 2001; Christensen, 2003). Pereira et al. (2001) and Christensen (2003) concluded that only $4 \mathrm{~mL}$ of acetonitrile are enough for efficiently extract PAHs from sample of as high as $160 \mathrm{mg}$ of atmospheric particulate or from $10 \mathrm{mg}$ of diesel soot.

\subsubsection{Extraction time}

One of the variables requiring the strictest control during the extraction procedure is temperature. Avoiding thermal damage of the extracts and loss of volatile components while the efficiency of extraction is maintained should be the main purpose in this step. To achieve this objective, short extraction cycles and a water bath for cooling samples were used during the procedure.

$2.5 \mathrm{mg}$ of soot samples in $4 \mathrm{~mL}$ of acetonitrile were extracted by using different pulse regimes and different extraction times. Total sonication times were $1.5,3,6$, and $8 \mathrm{~min}$. Concentrations of extracted PAHs observed as a function of extraction times were very similar (most of the data are within 10\%). In view of these results, the sonication time of $1.5 \mathrm{~min}$ with $2 \mathrm{~s} / 2 \mathrm{~s}$ sonication/relaxation time was selected for extracting PAHs.

\subsection{Filtering}

Prior to the clean-up step by SPE, the solvent extracts were filtered in order to remove all the soot particles. The device consisted of a $0.2 \mu \mathrm{m}$ sealed hydrophobic PTFE membrane filter with PTFE housing and glass syringes of $5 \mathrm{~mL}$. This material resists to a wide range of solvents, including acetonitrile and acetone. Upon extract filtration (volume was in the range $0.1-0.4 \mathrm{~mL}$ depending on soot sample) the filter was rinsed with $1 \mathrm{~mL}$ of acetonitrile.

\subsection{SPE procedure}

One of the main difficulties of the clean-up step is to select the appropriate solid phase. Manufactures offer a wide variety of materials, including silica bonded to various polar or unpolar groups (amino, diol, $\mathrm{C}_{18}$, cyano...). Different types of SPE adsorbent phase were tested in order to determine the best one for PAHs purification. Although silica is the most common phase used in SPE clean-up, we found that it was not efficient for the purification of kerosene soot samples. Its retention capability is poor and consequently it was impossible to remove all unwanted species without losing PAHs. Our experiments have shown that only silica- $\mathrm{C}_{18}$ is able to retain PAHs strong enough to avoid losses during the clean-up procedure using methanol (in case of complete combustion) or acetone (in case of incomplete combustion and premixed flames). Glass columns must be employed instead of polymer cartridges since acetonitrile and acetone were used.

\subsubsection{Conditioning of the cleaning column}

The column should be conditioned with an organic solvent with a polarity similar to that of the sample. This is a necessary step since the column, frit and adsorbent may contain impurities that can interfere with the analysis, especially at low concentrations (Kiss et al., 1996). In addition, this process activates the octadecyl chains in the column which facilitates the retention of polarisable molecules (i.e. PAHs). The conditioning was carried out with a mixture acetonitrile: methanol $(1: 1)$ in the case of soot from complete combustion and with a mixture acetonitrile: acetone $(1: 3)$ in the case of soot from incomplete combustion and premixed flames.

\subsubsection{Loading}

The sample was passed through the column by gravity. Sample loading was followed by rinsing with $1 \mathrm{~mL}$ of acetonitrile to remove interferences.

\subsubsection{Drying of column}

It is performed under slight vacuum ( -400 mbar) during $40 \mathrm{~min}$ to avoid a loss of light PAHs. Drying of the column allows using the solvents which are not miscible with acetonitrile or methanol such as hexane, in the next elution step. Besides, this process facilitates the elution of the target analytes.

\subsubsection{Elution of PAHs}

As a result of multiple tests, we found that the best results were obtained using a mixture hexane: isopropanol $(2: 5 \mathrm{v} / \mathrm{v})$ as elution solvent. Hexane provides an efficient elution of PAHs and isopropanol is suitable for direct injection in RPLC without changing the solvent. Furthermore its toxicity is lower compared to that of other organic solvents such as toluene. The elution was carried out under vacuum $(-700$ mbar $)$.

\subsection{Application and validation of the method}

Fig. 1 summarizes the procedure for the determination of PAHs concentration in kerosene soot as a function of the combustion process. This protocol was applied to real kerosene and bio-kerosene soot samples from complete and incomplete combustion produced in open diffusion flames and premixed flames as described in the experimental section.

\subsubsection{PAHs calibration and identification}

Calibration curves were constructed by using seven concentration levels ranging from 3 to $100 \mathrm{ppb}$. Calibration curves, detection and quantification limits of the method for 17 analytes included in synthetic mixtures are presented in Table 1 . Calculations were based on the fluorescent peak area of each individual standard (except anthracene, fluoranthene and indeno[1,2,3-cd]pyrene for which UV signal was used). Calibration equations with good correlation coefficient $(>0.996)$ were obtained for all compounds over the total range of concentration. 


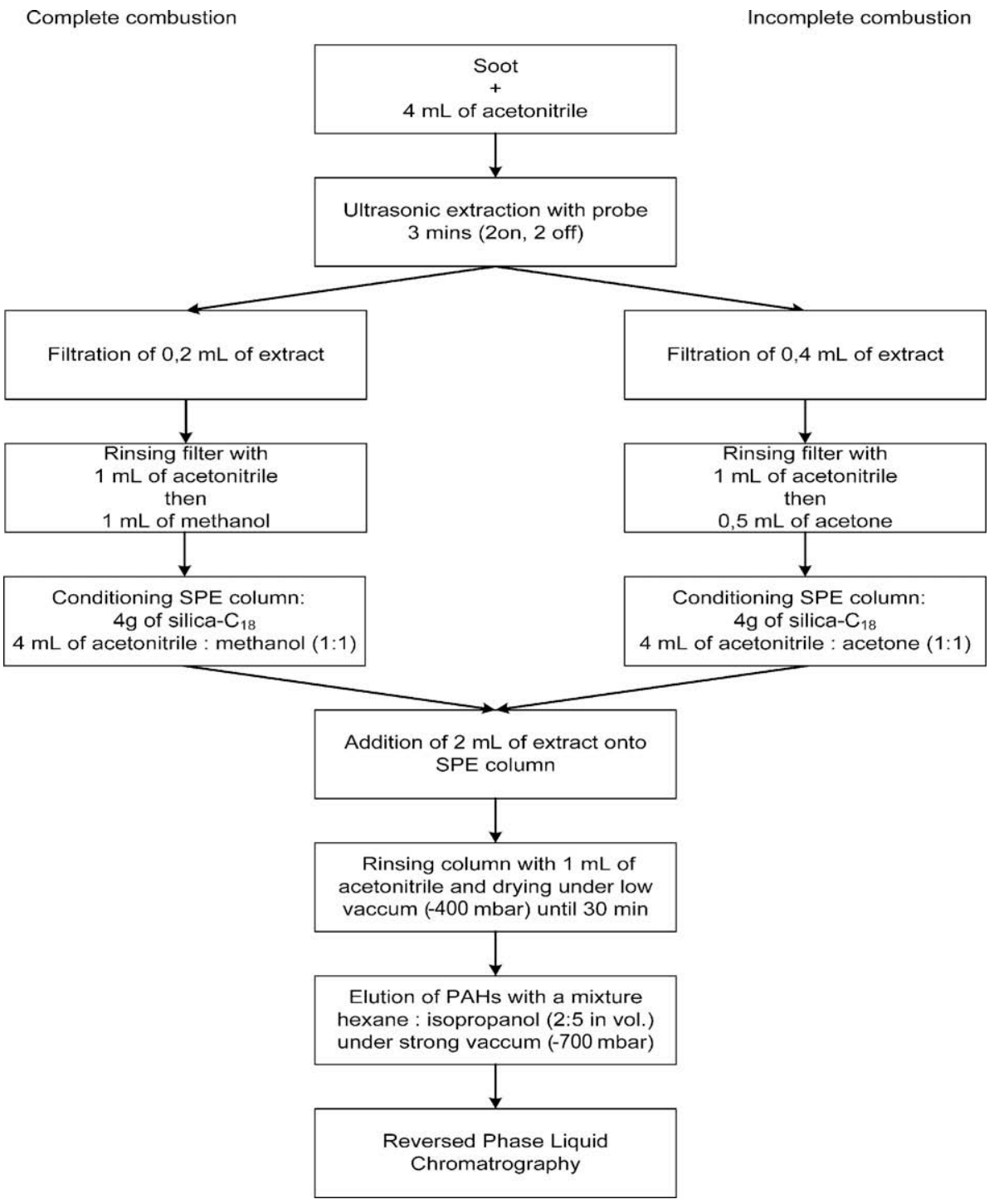

Fig. 1. Schematic representation of the method used for the determination of PAHs in kerosene soot according to combustion process in pool fires.

Table 1

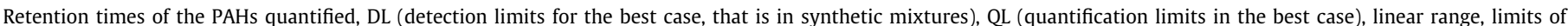
detection and quantification of the method for each compound analyzed ( $t$-student $=2.920,1-\alpha=095 ; n=3$ ).

\begin{tabular}{|c|c|c|c|c|c|c|}
\hline Compound & $\begin{array}{l}\text { Retention times } \\
(\min )(n=3)\end{array}$ & $\begin{array}{l}\text { DL (ng mL }{ }^{-1} \text { ) (best case } \\
\text { limits) }(n=7)\end{array}$ & $\begin{array}{l}\mathrm{QL}\left(\mathrm{ng} \mathrm{mL}^{-1}\right) \text { (best case } \\
\text { limits) }(n=7)\end{array}$ & $\begin{array}{l}\text { DL (ng mg }{ }^{-1} \\
\text { sample) }(n=3)\end{array}$ & $\begin{array}{l}\text { QL (ng mg }{ }^{-1} \\
\text { sample) }(n=3)\end{array}$ & $\begin{array}{l}\text { Linear range } \\
\left(\mathrm{ng} \mathrm{mL}^{-1}\right)\end{array}$ \\
\hline Naphthalene & 17.5 & 1.34 & 2.07 & 1.73 & 5.10 & $0-80$ \\
\hline 2-methylnaphthalene & 22.0 & 0.90 & 1.47 & 3.79 & 13.0 & $0-80$ \\
\hline Acenaphthylene & 23.1 & 0.09 & 0.12 & 3.76 & 12.9 & $0-45$ \\
\hline Acenaphthene & 24.2 & 0.49 & 0.95 & 3.60 & 12.3 & $0-25$ \\
\hline Fluorene & 26.9 & 0.68 & 1.44 & 1.67 & 5.70 & $0-80$ \\
\hline Phenanthrene & 32.0 & 0.49 & 0.82 & 0.65 & 2.22 & $0-100$ \\
\hline Anthracene & 37.8 & $5.83(\mathrm{UV})$ & $13.70(\mathrm{UV})$ & 5.92 & 20.3 & $0-100$ \\
\hline Fluoranthene & 48.2 & $10.3(\mathrm{UV})$ & 23.1 (OUV) & 15.9 & 54.6 & $0-80$ \\
\hline Pyrene & 50.1 & 0.41 & 1.12 & 0.68 & 2.33 & $0-85$ \\
\hline Benzo[a]anthracene & 63.7 & 0.04 & 0.08 & 1.38 & 4.71 & $0-100$ \\
\hline Chrysene & 64.3 & 0.01 & 0.02 & 2.05 & 7.00 & $0-40$ \\
\hline Benzo[b]fluoranthene & 73.0 & 0.05 & 0.13 & 0.77 & 2.63 & $0-100$ \\
\hline Benzo[k]fluoranthene & 76.2 & 0.04 & 0.09 & 0.76 & 2.60 & $0-25$ \\
\hline Benzo[a]pyrene & 78.4 & 0.07 & 0.17 & 0.64 & 2.16 & $0-40$ \\
\hline Dibenzo[ah]anthracene & 85.7 & 0.05 & 0.10 & 2.02 & 6.91 & $0-100$ \\
\hline Benzo[ghi]perylene & 87.1 & 0.09 & 0.17 & 2.24 & 7.77 & $0-80$ \\
\hline $\begin{array}{l}\text { Indeno[1,2,3- } \\
\text { cd]pyrene }\end{array}$ & 88.2 & 12.9 (UV) & 24.60 (UV) & 19.00 & 64.9 & $0-100$ \\
\hline
\end{tabular}


Table 1 also shows linear ranges of the PAHs studied, the detection limits and the quantification limits of the method. Detection limits were calculated by using spiked real soot samples at approx. 5 -fold the limit of detection of each compound, that is $6.5 \mathrm{ng} \mathrm{mg}^{-1}$ soot for each compound except for 2-methylnaphthalene, acenaphthene, acenaphthylene, fluoranthene, dibenzo[ah]anthracene, benzo[ghi]perylene and indeno[1,2,3-cd]pyrene for which soot spiked with $78 \mathrm{ng} \mathrm{mg}^{-1}$ soot was used.

Fig. 2 shows the chromatograms obtained for a kerosene soot sample from diffusion flame, overlapping the 17 PAHs synthetic mixture at $4.65 \mathrm{ppb}$ (in acetonitrile). As we can see, the baseline stability of soot extract is good and the retention times for each $\mathrm{PAH}$ are similar to those obtained for the synthetic mixture. The identification of peaks was carried out through UV/Visible spectra and retention times. In the chromatogram of kerosene soot we can identify 17 PAHs in the following order of retention: (1) Naph, (2) 2MNaph, (3) Acy, (4) Ace, (5) Fl, (6) Phe, (7) Ant, (8) Flu, (9) Pyr, (10) BaA, (11) Chry, (12) BbF, (13) BkF, (14) BaP, (15) DBahA, (16) BghiP, (17) IdP.

\subsubsection{Role of the clean-up step}

In order to evaluate the importance of the clean-up step in sootbound PAH analysis, we compared the PAHs levels in soot extracts obtained with and without SPE purification. Fig. 3 presents the results for kerosene soot from premixed flame (with previous purification and without previous purification). As can be seen from this figure, PAHs concentrations in raw sample are very high and consequently signal saturation was achieved in the fluorescence spectrum. Moreover, instable baseline probably due to interferences makes the PAHs quantification in raw samples not reliable. As can be seen from Fig. 3, the baseline stability for the purified sample (dilution factor $\sim 30$ ) chromatogram is higher than that recorded for the raw extract. We observed an obvious matrix effect for unclean samples. Indeed, comparing naphthalene signals at 17 min we can see similar height in both chromatograms even though purified extract is 30 -fold less concentrated than the non purified one, which evidences an outstanding fluorescence quenching.

Concentrations of PAHs measured in soot samples from kerosene premixed flames, with and without clean-up, are given in Table 2 (mean concentrations from three replicates are shown, $\mathrm{SD} \approx 10 \%$ ). Similar or higher concentrations than those in raw samples are observed in the extracts purified except for acenapthene and dibenzo[a,h]anthracene. Lower levels of acenapthene and dibenzo[a,h]anthracene in samples purified are probably due to difficulties in eluting these compounds from the SPE columns.

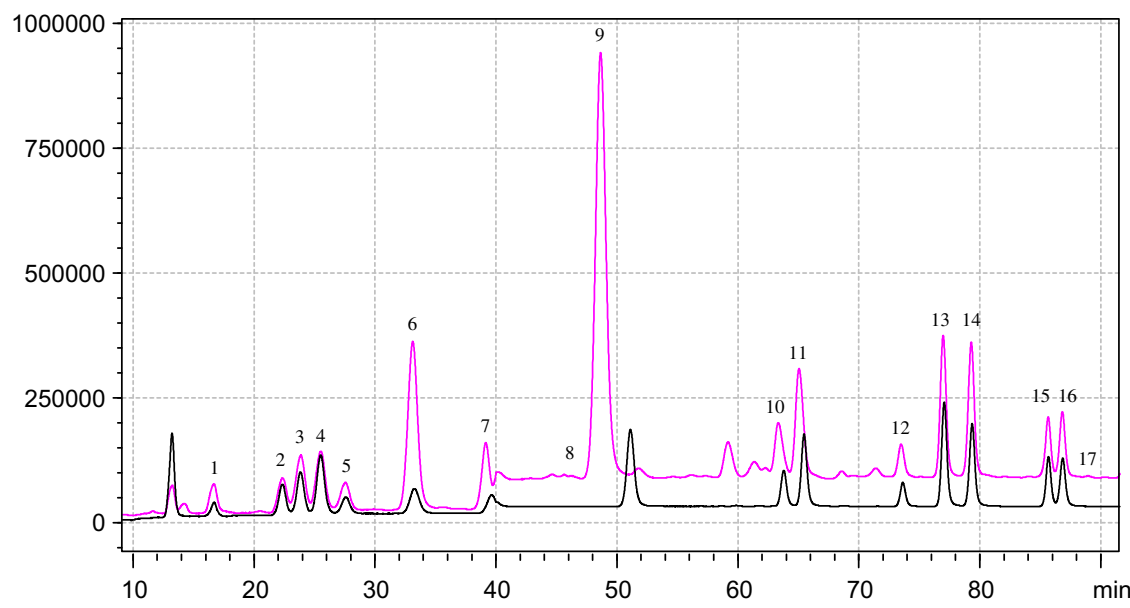

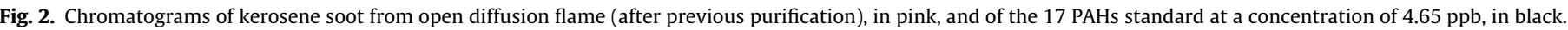
Fluorescence data. (For interpretation of the references to colour in this figure legend, the reader is referred to the web version of this article.)

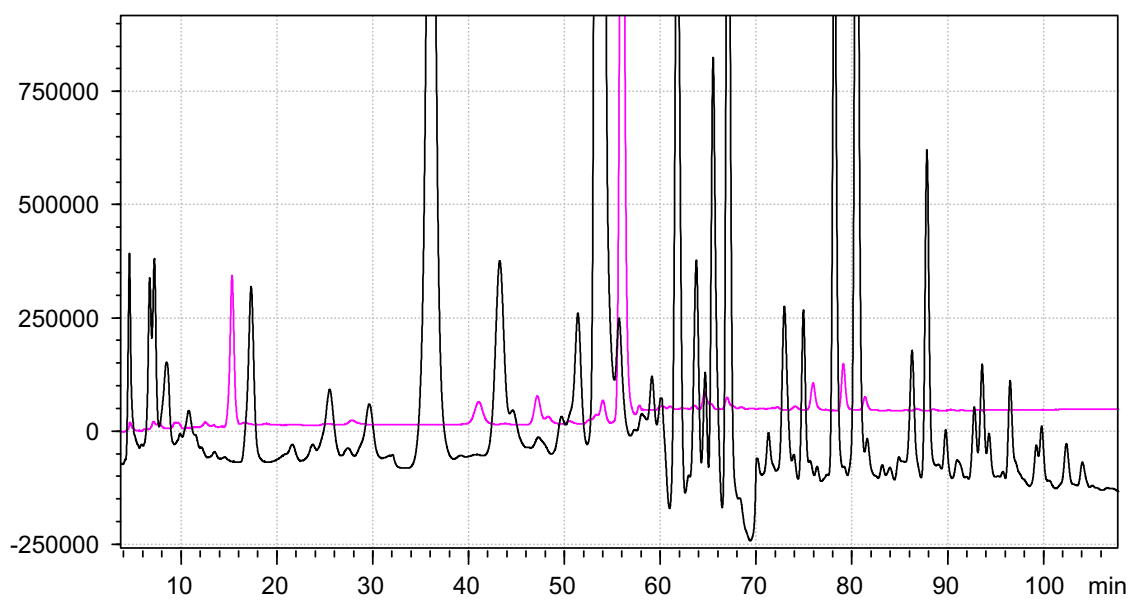

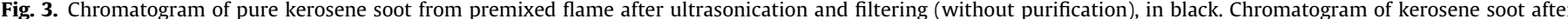

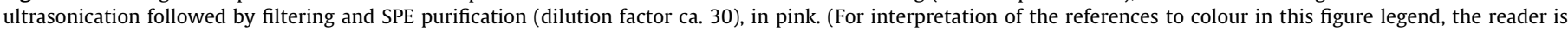
referred to the web version of this article.) 
Table 2

Comparison of PAH concentrations in soot samples from kerosene premixed flames measured with and without applying SPE procedure.

\begin{tabular}{|c|c|c|}
\hline \multirow[t]{2}{*}{ PAHs } & \multicolumn{2}{|c|}{ Concentration (ng mg ${ }^{-1}$ of soot) } \\
\hline & Without clean-up & With clean-up \\
\hline Naphthalene & 43 & 146 \\
\hline 2-methylnaphthalene & 23 & 32 \\
\hline Acenaphthylene & 19 & 61 \\
\hline Acenaphthene & 17 & 12 \\
\hline Fluorene & 1275 & 1254 \\
\hline Phenanthrene & 4425 & 6170 \\
\hline Anthracene & 1732 & 2317 \\
\hline Fluoranthene & 2838 & 4209 \\
\hline Pyrene & 6200 & 9118 \\
\hline Benzo[a]anthracene & 872 & 868 \\
\hline Chrysene & 493 & 627 \\
\hline Benzo[b]fluoranthene & 484 & 483 \\
\hline Benzo[k]fluoranthene & 243 & 242 \\
\hline Benzo[a]pyrene & 1677 & 1621 \\
\hline Dibenzo[a,h]anthracene & 771 & 521 \\
\hline Benzo[g,h,i]perylene & 2043 & 2066 \\
\hline Indeno[ $1,2,3-c d]$ pyrene & ${ }^{\mathrm{a}} \mathrm{NQ}$ & ${ }^{\mathrm{a}} \mathrm{NQ}$ \\
\hline
\end{tabular}

a NQ: not quantified.

Alternatively, dibenzo[a,h]anthracene might co-elutes with interferences leading to increase of the peak area in the chromatogram of the raw sample.

\subsubsection{Recovery assays}

Precision and accuracy of the method was evaluated through replicate measurements of spiked soot samples (Tables 3 and 4). The use of deuterated standard PAHs was not possible because of their degradation by the ultrasonic probe device. As a matter of fact, ultrasound tests carried out with chrysene- $\mathrm{d}_{12}$ and phenanthrene- $\mathrm{d}_{10}$ demonstrated that these compounds are not stable under extraction conditions. Several samples containing variable amounts of kerosene soot (5-15 mg in $4 \mathrm{~mL}$ of acetonitrile) were spiked previously to the extraction, with 10 and $30 \mu \mathrm{L}$ of a 16 EPA PAHs standard mixture at 6.5 and $26 \mathrm{ppm}$ in acetonitrile respectively, that is two levels of concentration (low: about $6.5 \mathrm{ng} \mathrm{mg}^{-1}$ soot, and high: $78 \mathrm{ng} \mathrm{mg}^{-1}$ soot). Spiked samples were homogenized by manual stirring for $1 \mathrm{~min}$ and kept at $4{ }^{\circ} \mathrm{C}$ for $24 \mathrm{~h}$ before analysis by the same procedure than described in the experimental section for real samples of soot. Table 3 shows PAHs recoveries (from three replicates) obtained using the proposed analytical method.

The observed results demonstrated that the analytical method produced almost the complete recovery of most of the PAHs studied and good precision. Acenaphthene and acenaphthylene showed the lowest recoveries (50\% and 65\%, respectively) and 4-ring PAHs exhibited the highest recoveries (approx. 95\%) from the soot matrix. Recovery values from the seven replicate measurements averaged at $84.7 \%$ for soot samples with \%RSD values of $7.4 \%$. Similar recoveries were reported by other authors (Fischer et al., 1994; Sun et al., 2006). Concerning acenaphthene, this compound seems to be strongly retained by silica- $\mathrm{C}_{18}$ SPE column and was found to elute hardly from the SPE column even for synthetic mixtures.

Recoveries and standard deviations in the cases of 2-methylnaphthylene, acenaphthylene, acenaphthene, anthracene, fluoranthene, dibenzo[ah]anthracene, benzo[ghi]perylene and indeno[1,2,3-cd]pyrene were calculated by using the high level because due to their quantification limits (higher than $6.5 \mathrm{ng} \mathrm{mg}^{-1}$ soot). The other PAHs were evaluated through the low level.

\subsubsection{Application to kerosene and bio-kerosene combustion soot}

Field samples (six samples of kerosene and three of bio-kerosene soot for both complete and incomplete combustion) were
Table 3

Recovery assays in real soot samples spiked at two levels at two levels concentration (low: $6.5 \mathrm{ng} \mathrm{mg}^{-1}$ sample and high: $78 \mathrm{ng} \mathrm{mg}^{-1}$ sample) $(n=3)$.

\begin{tabular}{|c|c|c|c|c|}
\hline PAHs & 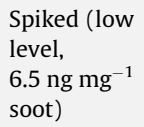 & $\begin{array}{l}\text { Found } \\
\text { (ng mg } \\
\text { soot) }\end{array}$ & $\begin{array}{l}\text { Spiked } \\
\text { (high level, } \\
78 \mathrm{ng} \mathrm{mg}^{-1} \\
\text { soot) }\end{array}$ & $\begin{array}{l}\text { Found } \\
\text { (ng mg } \mathrm{mg}^{-1} \\
\text { soot) }\end{array}$ \\
\hline Naphthalene & 6.5 & 4.6 & 78.0 & 58.5 \\
\hline 2-methylnaphthalene & 6.5 & a & 78.0 & 60.0 \\
\hline Acenaphthylene & 6.5 & a & 78.0 & 50.7 \\
\hline Acenaphthene & 6.5 & a & 78.0 & 39.0 \\
\hline Fluorene & 6.5 & 4.2 & 78.0 & 56.2 \\
\hline Phenanthrene & 6.5 & 6.0 & 78.0 & 75.0 \\
\hline Anthracene & 6.5 & a & 78.0 & 77.2 \\
\hline Fluoranthene & 6.5 & a & 78.0 & 74.9 \\
\hline Pyrene & 6.5 & 6.0 & 78.0 & 73.3 \\
\hline Benzo[a]anthracene & 6.5 & 5.8 & 78.0 & 71.6 \\
\hline Chrysene & 6.5 & 5.9 & 78.0 & 72.3 \\
\hline Benzo[b]fluoranthene & 6.5 & 6.0 & 78.0 & 72.1 \\
\hline Benzo[k]fluoranthene & 6.5 & 6.1 & 78.0 & 75.5 \\
\hline Benzo[a]pyrene & 6.5 & 5.9 & 78.0 & 73.3 \\
\hline Dibenzo[ah]anthracene & 6.4 & a & 78.0 & 71.0 \\
\hline Benzo[g,h,i]perylene & 6.5 & a & 78.0 & 65.5 \\
\hline $\begin{array}{l}\text { Indeno[1,2,3- } \\
\text { cd]pyrene }\end{array}$ & 6.5 & $\mathrm{a}$ & 78.0 & 69.4 \\
\hline
\end{tabular}

${ }^{\text {a }}$ Under quantification limit.

Table 4

Replicate spiked samples used for evaluation of accuracy and precision of the analytical methodology. Standard deviations were calculated for the low level (6.5 $\mathrm{ng} \mathrm{mg}^{-1}$ soot) in all the cases except for 2-methylnaphthalene, acenaphthene, acenaphthylene, anthracene, dibenzo[a,h]anthracene, benzo[g,h,i]perylene and indeno[1,2,3-cd]pyrene for which the high level $\left(78 \mathrm{ng} \mathrm{mg}^{-1}\right.$ soot) was used due to their quantification limits $(n=3)$.

\begin{tabular}{lllc}
\hline PAHs & Number of rings & Recovery (\%) & RSD (\%) \\
\hline Naphthalene & 2 & 70.8 & 6.9 \\
2-methylnaphthalene & 2 & 76.9 & 8.5 \\
Acenaphthylene & 2 & 65.0 & 16.8 \\
Acenaphthene & 2 & 50.0 & 19.2 \\
Fluorene & 3 & 64.6 & 6.1 \\
Phenanthrene & 3 & 92.3 & 3.1 \\
Anthracene & 3 & 98.9 & 9.9 \\
Fluoranthene & 4 & 96.0 & 2.7 \\
Pyrene & 4 & 92.3 & 3.0 \\
Benzo[a]anthracene & 4 & 89.2 & 7.1 \\
Chrysene & 4 & 90.8 & 12.1 \\
Benzo[b]fluoranthene & 5 & 92.3 & 3.8 \\
Benzo[k]fluoranthene & 5 & 93.8 & 2.8 \\
Benzo[a]pyrene & 5 & 90.8 & 3.1 \\
Dibenzo[ah]anthracene & 5 & 91.0 & 7.8 \\
Benzo[g,h,i]perylene & 6 & 83.9 & 9.8 \\
Indeno[1,2,3-cd]pyrene & 6 & 89.0 & 7.9 \\
\hline
\end{tabular}

analyzed to demonstrate the analytical accuracy and precision of the method through the sampling and analysis procedure. Standard deviations for each PAH are shown in Table 5, and as we can see, these values are similar for all the samples evaluated. Only slightly higher values of standard deviations were obtained for low concentrations of PAHs compared to those of high concentrations but similar standard deviations for all the samples analyzed (kerosene and bio-kerosene soot, and soot from complete and incomplete combustion) were achieved in spite of in the case of soot from incomplete combustion, higher volumes of samples were taken for the purification step $(0.4 \mathrm{~mL}$ vs. $0.2 \mathrm{~mL}$ in the case of complete combustion). Standard deviation of the method is low for 3-5 ring PAHs (about 3\%) and slightly higher (about $10 \%$ for heavier PAHs). Only acenaphthene, acenaphthylene and 2-metylnaphthalene exhibited non satisfactory standard deviations (about 20\%) probably due to the fact that acenaphthene and acenaphthylene 


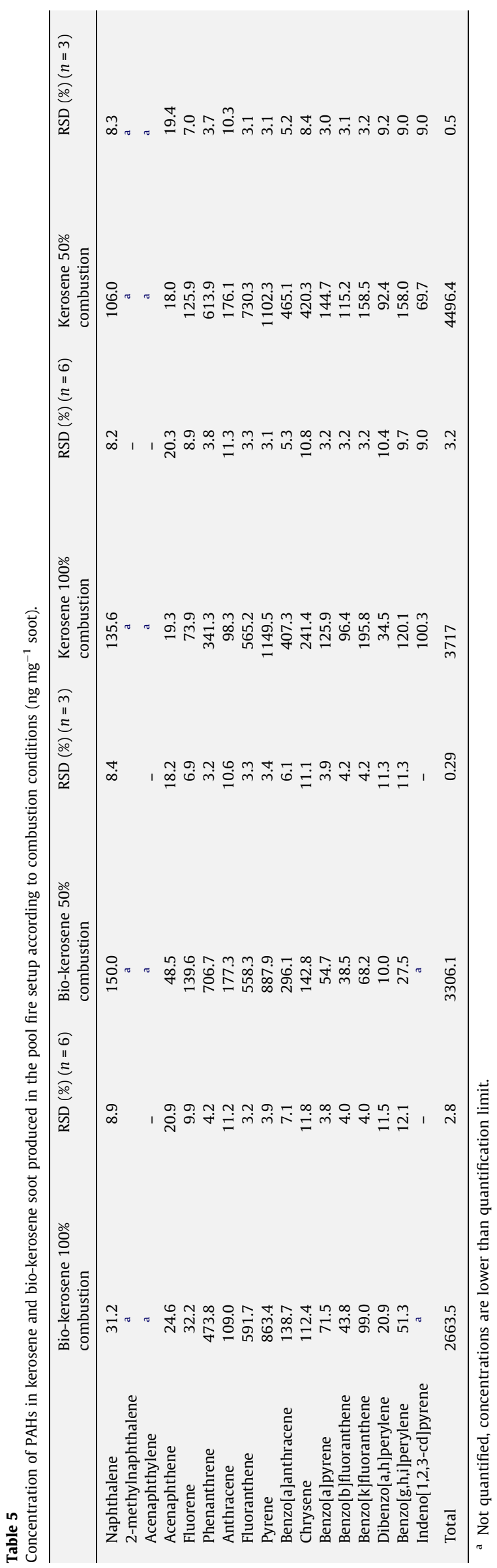

have high volatility and low concentrations in samples and exhibit high relationship medium polarizability/molecular weight which accounts for their strong retention in SPE cartridges and the difficulty for desorbing them in this kind of tubes.

The heaviest PAHs exhibited standard deviations around 10\% probably due to the strong retention in SPE cartridges too.

In all the cases, reproducibility is acceptable. Most of standard deviations are around $4 \%$ (certainly reproducible) and no significant differences in standard deviations among samples from different fuels (bio-kerosene or pure kerosene) or combustion procedures ( $100 \%$ or $50 \%$ combustion) exist.

On the other hand, and as we can see from Table 4, standard deviation of PAHs are similar to those found in recovery experiments. That is, analytical methodology is the first responsible of variations in final results. Protocol of soot production seems to be very reproducible.

As a summary we can state that the precision of the method is excellent because in most of the cases the RSD are lower than 10\% (Table 5). Accuracy and Precision for Analysis of PAH from Field Samples is similar to that of the analytical methodology (see recoveries in spiked samples, Table 4 ).

Maximum levels of PAHs were observed in soot samples produced by burning pure kerosene, the total concentration of PAHs being near $16 \%$ lower in the case of complete combustion. Maximum concentration of these compounds was found when using pure kerosene as fuel regardless of the combustion conditions. As one could expect, addition of RME to pure kerosene (bio-kerosene) decreases the concentration of PAHs in soot by about $30 \%$ regardless of combustion conditions. The most abundant compounds in decreasing concentration order were: pyrene, fluoranthene, phenanthrene, benzo[a]anthracene and chrysene.

\section{Conclusion}

An efficient and reliable analytical methodology for the determination of PAHs in laboratory generated kerosene soot was developed. This method is based on ultrasonic-assisted extraction, purification through silica- $\mathrm{C}_{18}$ phase and RPLC analysis.

Extraction of PAHs from soot using an ultrasonic probe device was shown to give high extraction efficiencies at relatively short extraction times (a few minutes). The SPE procedure employed in the present study for purification of soot extracts was found to be more efficient when used with $\mathrm{C}_{18}$ cartridges instead of conventionally used silica. In addition, it was shown that the optimum SPE conditions (e.g. solvent) are different for soot samples produced under different combustion conditions and from different fuels.

Quantification limits ranged from $0.64 \mathrm{ng} \mathrm{mg}^{-1}$ soot for benzo[a]pyrene (with fluorescence detection) to $19.0 \mathrm{ng} \mathrm{mg}^{-1}$ soot for indeno[1,2,3-cd]pyrene (with UV detection) and recoveries from spiked real soot samples were around 90\% in most cases.

The method was applied to the analysis of the PAH content in kerosene and bio-kerosene (kerosene + RME) soot samples produced under different combustion conditions: pool fires and premixed flames. It was shown that the blending of kerosene with RME decreased by near $30 \%$ the concentration of soot-bound PAHs.

\section{Acknowledgements}

The authors are grateful to Valérie Rondeau (Shimadzu France) for her help with the fluorescence detector. Partial financial support from ESA through the contract 15091/01/NL/SH-CCN No. 002, MAP Project numbers AO-99-001 AO-99-085, is gratefully acknowledged. 


\section{References}

Albinet, A., Leoz-Garziandia, E., Budzinski, H., Villenave, E., 2006. Simultaneous analysis of oxygenated and nitrated polycyclic aromatic hydrocarbons on standard reference material 1649a (urban dust) and on natural ambient air samples by gas chromatography-mass spectrometry with negative ion chemical ionisation. J. Chromatogr. A 1121, 106-113.

Christensen, A., 2003. PAHs in Exhaust Emissions of Mobile Sources, Sampling and Determination. Ph.D. Thesis. Department of Analytical Chemistry, Stockholm University, Sweden.

Christensen, A., Östman, C., Westerholm, R., 2005. Ultrasound-assisted extraction and on-line LC-GC-MS for determination of polycyclic aromatic hydrocarbons $(\mathrm{PAH})$ in urban dust and diesel particulate matter. Anal. Bioanal. Chem. 381, 1206-1216.

Dagaut, P., Gail, S., 2007. Chemical kinetic study of the effect of a biofuel additive on jet-A1 combustion. J. Phys. Chem. A 111, 3992-4000.

Fischer, R., Kreuzig, R., Bahadir, M., 1994. Extraction behavior of polycyclic aromatic hydrocarbons from soil samples. Chemosphere 29, 311-317.

Fladung, N.C., 1995. Optimization of automated solid-phase extraction for quantitation of polycyclic aromatic hydrocarbons in aqueous media by highperformance liquid chromatography-UV detection. J. Chromatogr. A 692, 21-26.

Frenklach, M., 2002. Reaction mechanism of soot formation in flames. Phys. Chem. Chem. Phys. 4, 2028-2037.

Gustafsson, O., Gschwend, P.M., 1997. In: Eganhouse, R.P. (Ed.), Molecular Markers in Environmental Geochemistry. American Chemical Society, Washington, DC.

Haynes, B.S., Wagner, H.G., 1981. Soot Format. Prog. Energy Combust. Sci. 7, 229 273.

Hechler, U., Fisher, J., Plagemann, S., 1995. Comparison of different extraction methods for the determination of polycyclic aromatic hydrocarbons in soil. Fresenius J. Anal. Chem. 351, 591-592.
IPCC, 2001. Climate change 2001: the scientific basis. In: Houghton, J.T., Ding, Y., Griggs, D.J., Noguer, M., van der Linden, P.J., Dai, X., Maskell, K., Johnson, C.A. (Eds.), Contribution of Working Group I to the Third Assessment Report of the Intergovernmental Panel on Climate Change. Cambridge University Press, Cambridge, United Kingdom and New York, NY, USA.

Jonker, M.T.O., Koelmans, A.A., 2002. Extraction of polycyclic aromatic hydrocarbons from soot and sediment: solvent evaluation and implications for sorption mechanism. Environ. Sci. Technol. 36, 4107-4113.

Kiss, G., Varga-Puchony, Z., Hlavay, J., 1996. Determination of polycyclic aromatic hydrocarbons in precipitation using solid-phase extraction and column liquid chromatography. J. Chromatogr. A 725, 261-272.

Lamprecht, G., Huber, J.F.K., 1992. Direct determination of benzo[a]pyrene in oil distillates by on-line two-dimensional HPLC with column switching. Chromatographia 34, 376-380.

Lelièvre, S., Bedjanian, Y., Pouvesle, N., Delfau, J.L., Vovelle, C., Le Bras, G., 2004 Heterogeneous reaction of ozone with hydrocarbon flame soot. Phys. Chem. Chem. Phys. 6, 1181-1191.

Marín, A., López-González, A., Barbas, C., 2001. Development and validation of extraction methods for determination of zinc and arsenic speciation in soils using focused ultrasound: application to heavy metal study in mud and soils. Anal. Chim. Acta 442, 305-318.

Nascentes, C.C., Korn, M., Arruda, M.A.Z., 2001. A fast ultrasound-assisted extraction of $\mathrm{Ca}, \mathrm{Mg}$, Mn and $\mathrm{Zn}$ from vegetables. Microchem. J. 69, 37-43.

Pereira, P.A.D., de Andrade, J.B., Miguel, A.H., 2001. Determination of 16 priority polycyclic aromatic hydrocarbons in particulate matter by HRGC-MS after extraction by sonication. Anal. Sci. 17, 1229-1231.

Sun, P., Weavers, L.K., Taerakul, P., Walker, H.W., 2006. Characterization of polycyclic aromatic hydrocarbons (PAHs) on lime spray dryer (LSD) ash using different extraction methods. Chemosphere 62, 265-274. 